\title{
Development of insulation system for variable speed driven motors; performance of a corona resistant magnet wire
}

\author{
Tomi Nuorala ${ }^{1}$, Janne Lehtonen ${ }^{2}$, Markus Takala ${ }^{1}$ \\ ${ }^{1} A B B O y, B U$ Motors and Generators, Finland \\ ${ }^{2} A B B O y, B U$ Transformers, Finland
}

\begin{abstract}
The amount of variable speed drive (VSD) motors and generators is growing constantly, but VSD use causes partial discharges (PDs) which are the most common reason for the winding damage. Magnet wire manufacturers have developed products that are more resistant against PDs. The objectives of this study were to resolve if the other properties of a corona resistant (CR) magnet wire are sufficient compared to reference wire. Dimension measurement, mandrel, peel, breakdown voltage and pin hole tests were made to both wires.
\end{abstract}

\section{Introduction}

The amount of VSD motors and generators is growing constantly. VSD drives allow lower running costs of motors, but in turn the higher voltage spikes by frequency converter may cause premature failure of otherwise reliable motor. Failure analyses of motors have given evidence of PDs as a reason of damage. Magnet wire manufacturers have developed products that are more resistant against PDs [1]. Such enamelled wires have a three-layered structure: a partial discharge resistant coating film is placed between normal enamel coating films to compensate for the weak mechanical properties of the aforementioned enamelled wires. Even with such a precaution, their electrical properties are vulnerable to degradation caused by mechanical stress such as elongation, and so far, they have failed to bring remarkable improvement to the performance of motors in actual operation. [2-4].

This paper presents a study where one commercially available CR wire was tested to see if the properties of CR wire are sufficient compared to the reference wire. The Voltron ${ }^{\circledR}$ enamel used as a base coat is from DuPont.

\section{Experimental procedure}

Figure 1 presents the excellent PD resistance of the corona resistant wire. The main question after the study was, if the enamel adhesion to copper is sufficient. To define this, various tests have been made for the both wires studied. In addition to this, other tests are performed to find out the properties of the new wire when compared to reference wire. All tests are based on IEC standards.

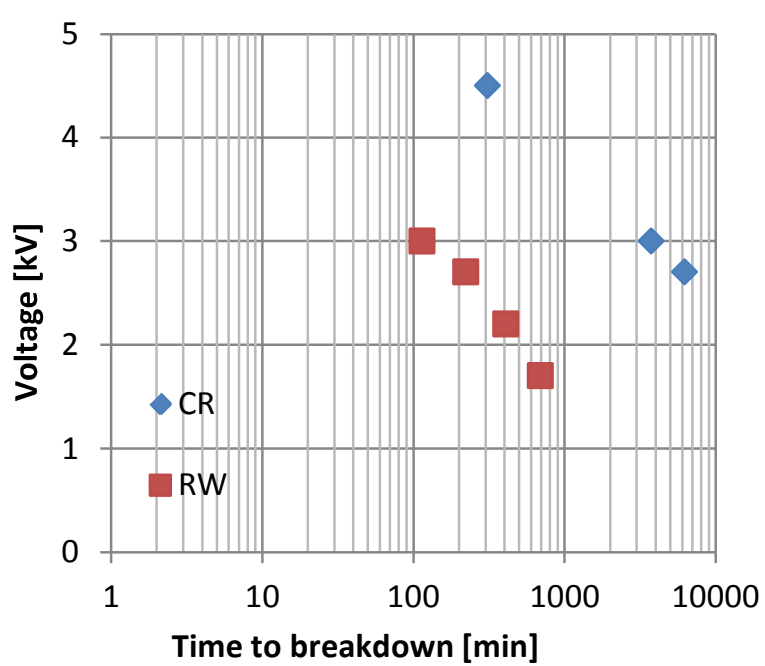

Fig. 1 - Time to breakdown of unimpregnated twists of reference wire $(\mathrm{RW})$ and corona resistant $(\mathrm{CR})$ wire.

IEC60851 describes test methods for winding wire [5]. The dimension measurement, mandrel, peel, breakdown voltage and pin hole tests were performed.

\subsection{Dimension measurement}

The magnet wire, the conductor and the enamel layer of the wire have dimension tolerances for every nominal diameter given in standard IEC 60317-1 [6]. Dimension measurement is based on standard IEC 60851-2 [7]. The measurement is divided into two parts.

1. diameter measurement with enamel insulation using micrometer, and

2. diameter measurement without enamel insulation using micrometer

The criteria for round copper wires are given in standard IEC 60317-0-1 [6].The criteria are overall diameter, conductor tolerance and insulation thickness. This measurement is made for a $30 \mathrm{~cm}$ long wire sample. The sample has to be straightened before measuring to get reliable results. The thickness of the wire is measured at three different points with micrometer. The dimensions are measured in three angles: $0^{\circ}, 120^{\circ}$ and $240^{\circ}$ at each point. The points are on $10 \mathrm{~cm}$ distance from each other. 


\subsection{Mandrel test}

The adhesion between enamel and copper, i.e., how well the insulation layer is attached with the conductor, can be tested with a mandrel test. This test is performed according to standard IEC 60851-3 [8]. In mandrel test a wire is wound around a core which diameter is from $1 \mathrm{x}$ to $5 \mathrm{xD}$, where $\mathrm{D}$ is the diameter of the wire. Thus, the highest mechanical stress is caused for $1 \mathrm{xD}$ core. Figure 2 presents the test bench for mandrel test.

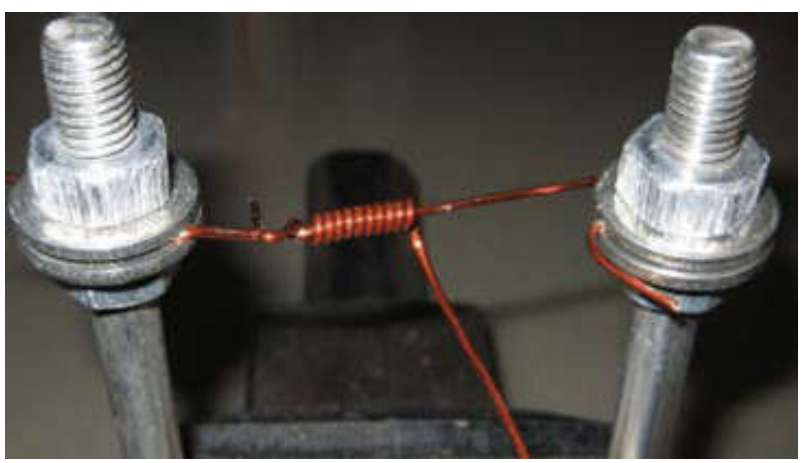

Fig. 2 - The test bench for winding the mandrel. The core wire has same diameter as the wire tested $(1 \mathrm{xD})$.

The acceptance criteria and mandrel diameters are given in standard IEC 60317-0-1 [6]. The enamel coating shall show no cracks after the wire has been wound on the mandrel. The main purpose of this test is to see how strong the $\mathrm{CR}$ wire is against mechanical stress compared to the reference wire.

\subsection{Peel test}

Like mandrel test, also the peel test investigates the adhesion between enamel and copper in the magnet wire. In peel test, magnet wire is rotated in the longitudinal direction. The peel test is performed according to standard IEC 60851-3 [8]. The criteria for acceptance are given in standard IEC 60317-0-1 [6]. This test is only done for wires that are at least $1 \mathrm{~mm}$ in diameter because thinner wires break quite easily during the test. Revolutions for peel test is calculated with Equation 1.

$$
\mathrm{R}_{\mathrm{w}}=\frac{\mathrm{K}}{\mathrm{d}_{\mathrm{nom}}}
$$

where $R_{w}$ is revolutions of the wire, $K$ is constant, 110 $\mathrm{mm}$ for polyester and polyesterimide coated wires [9], $\mathrm{d}_{\text {nom }}$ is a nominal conductor diameter without insulation layer. The length of the wire sample is always $50 \mathrm{~cm}$. The insulation layer is removed from opposite sides of the wire before rotating. The wire should show no loss of adhesion after peeling and rotating [8]. Figure 3 shows a result of peel test.

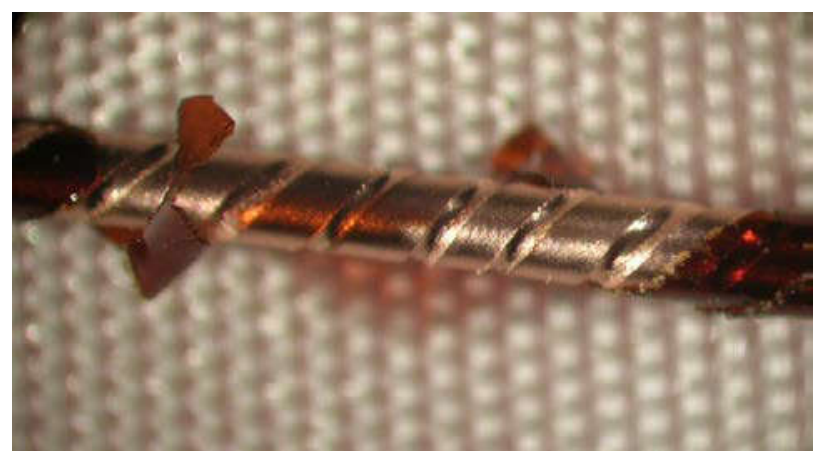

Fig. 3 - Faulty wire after peel test. Insulation layer has lost its adhesion to copper.

\subsection{Breakdown voltage test}

The breakdown voltage test measures dielectric strength of the insulation layer. The breakdown test is based on standard IEC 60851-5 [10]. The wire is approved when 4 samples out of 5 exceed the limit voltage of standard IEC 60317-0-1. The minimum breakdown voltage for twisted pairs is given by IEC standard. For grade 2 and wire dimensions $1.0-2.5 \mathrm{~mm}$ it is $5.0 \mathrm{kV}$ ac [6]. Voltage rise time of $500 \mathrm{~V} / \mathrm{s}$ was used [10]. In this study measurements were also conducted with dc voltage.

\subsection{Pin hole test}

The purpose of the pin hole test is to find and count the number of defects in magnet wire insulation. The pin hole test is based on standard IEC 60851-5 [10]. This test is meant for winded and after that dismantled winding coils. The maximum number of pin holes for grade 2 standard wires is 3 . For grade 2 polyurethane wires maximum is 5 . These values are defined in standard for a five meter long sample [6].

\section{Results and discussion}

\subsection{Dimension measurement}

The CR wire passed diameter measurements. Some differences between different diameters were detected but they all were very small.

The conductor tolerances were calculated by measuring the conductor before and after burning and cleaning the enamel, and comparing those values to the minimum diameters given by standard [6]. In Figure 4 conductor tolerance for both wires and diameters are presented. 


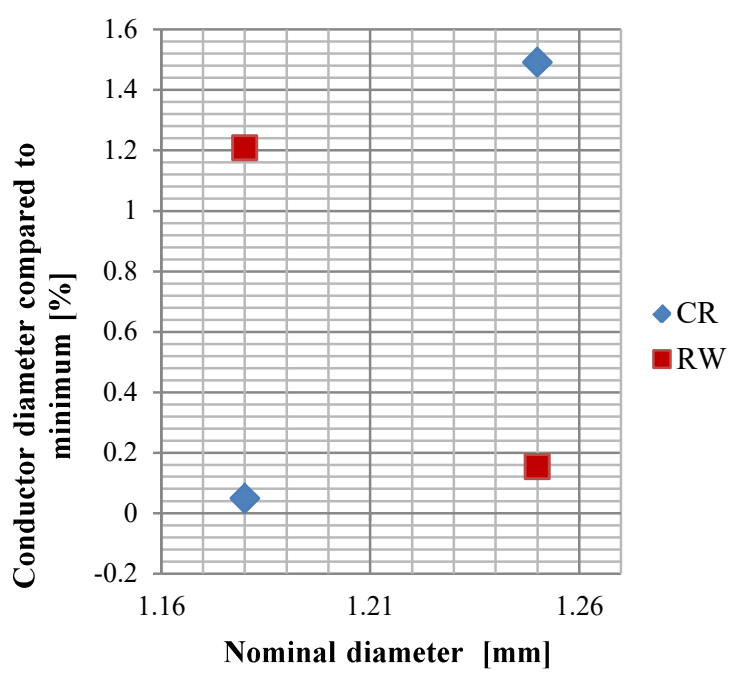

Fig. 4 - Conductor tolerance for two nominal diameters. Conductor diameter is compared to the minimum required value.

The insulation thicknesses were obtained by reducing the conductor diameter from the total diameter of the wire. Each measuring point was measured with and without insulation layer. In Figure 5 range of insulation thickness for two nominal diameters is presented. Insulation thicknesses are in the middle of the tolerance range.

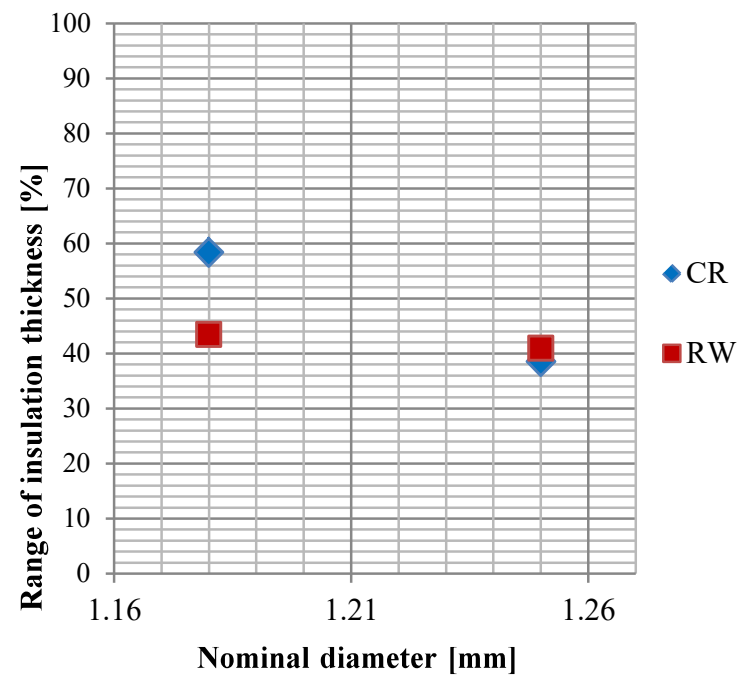

Fig. 5 - Range of insulation thickness for two nominal diameters. $0 \%$ correspond the bottom level of IEC standard.

\subsection{Mandrel test}

At room temperature no cracks or loss of adhesion was detected in any of the tested wires during the test. All wires passed the mandrel test.

\subsection{Peel test}

The results of the peel test were identical. No cracks or loss of adhesion was detected in any of the tested wires. All wires passed the peel test.

\subsection{Breakdown voltage test}

The breakdown voltage test was performed with dc and ac voltages. Figure 6 presents the average breakdown voltage of wires. The CR wire passed both of these tests. Some differences in the results between the wires were observed. The effect of the voltage waveform needs to be investigated more specifically.

Figure 7 presents the dielectric strength as a function of insulation thickness. In each test, except CR with dc voltage, the breakdown strength decreases when the insulation thickness increases. This indicates that increasing the insulation thickness does not improve the breakdown strength of the wire.

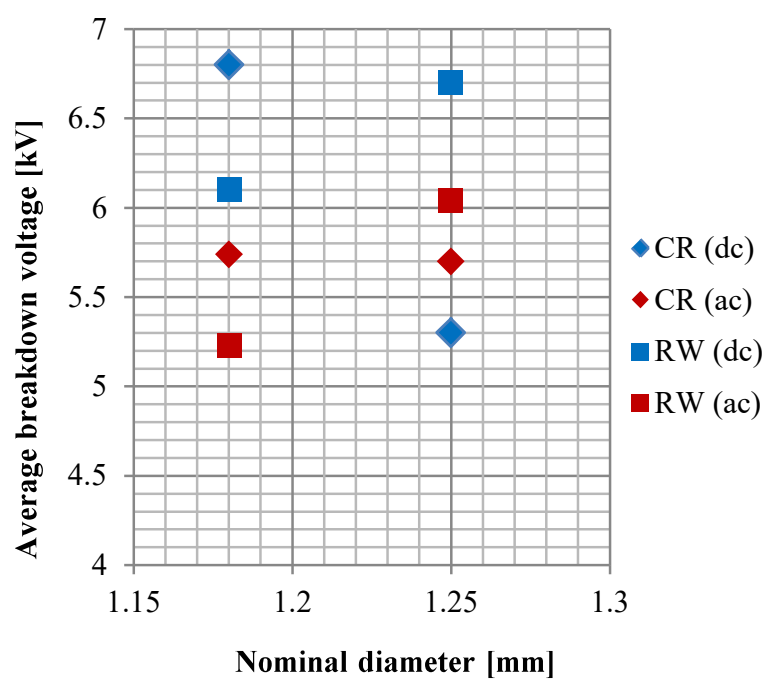

Fig. 6 - The average breakdown voltage for two nominal diameters of magnet wire.

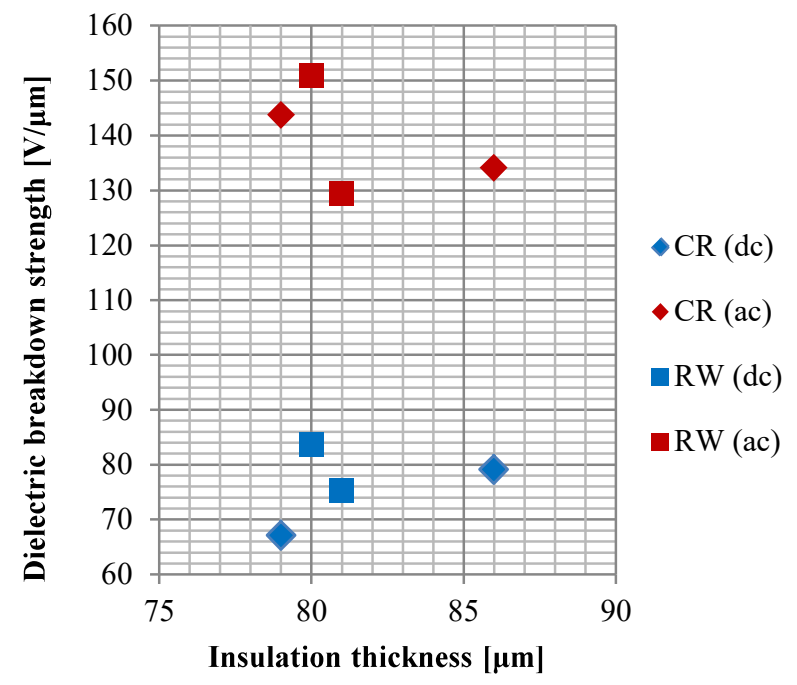

Fig. 7 - Range of dielectric breakdown strength as a function of insulation thickness. 


\subsection{Pin hole test}

The CR wire passed also the pin hole test. No differences when compared with the reference wire were detected. The test was performed in the winding department.

Winding and dismantling of the $\mathrm{CR}$ wire winding was normal and nothing unusual was detected. The number of pin holes was two for CR and one for the reference wire. Both wires are easy to process in windings.

\section{Discussion and conclusions}

Testing of magnet wires included some challenges. To get reliable results, the number of samples should be rather high. Each test should also be performed identically. The repeatability in long time test series or tests with a large number of samples should be improved. With only a small number of specimens it is easy to repeat the same test for all specimens. During the aging tests that may last for several months, the testing method will vary a bit, especially if the tests are made by hands. This will be emphasized if the tests are performed by several persons. The more mechanical and automatic a test is, the more reliable are the results.

The objectives of this study were to resolve if the properties of the new corona resistant wire are sufficient when compared to the reference wire.

Laboratory tests confirmed that the properties of the new wire fulfil the requirements.

Based on the results of this study there are several sections in which one can continue investigations and development. The test methods for magnet wire testing could be developed to improve the repeatability and thereby the reliability of the test results. The CR wire proved its quality in the tests conducted in this study. However, also practical tests with prototypes will be needed. One possible way to continue research is to obtain and investigate also other alternative corona resistant wires.

Combining good characteristics of existing technologies may give better results than evaluating something totally new.

\section{References}

[1] Beeckman, R.J. (1999). Inverter drive issues and magnet wire responses. Proceedings Electrical Insulation Conference and Electrical Manufacturing \& Coil Winding Conference (26-28 October 1999), p. 139-141. Cincinnati, OH, USA.

[2] F.R. Bohm, H. Schindler and K. Nagel, "VoltronTM- A New Generation of Wire Enamel for the Production of Magnet Wires for Inverter Fed Motors", Int'l. Electr. Insul. Conf. (INSUCON), pp. 357-361, 2002.
[3] M. Mesaki and H. Goda, "Hybrid Composites of Polyamide-imide and Silica Applied for Wire Insulation", IEEE Electr. Insul. Conf. (EIC) / Electr. Manufacturing \& Coil Winding (EMCW) Expo, 2001.

[4] T. Ozaki, T. Imai, F. Sawa, T. Shimizu and F. Kanemitsu, "Partial Discharge Resistant Enameled Wire”, Int'l. Sympos. Electr. Insulating Materials (ISEIM), Vol. 1, pp. 184-187, 2005.

[5] International Electrotechnical Commission (1996). IEC 60851-1 Winding wire - Test methods - Part 1:General.

[6] International Electrotechnical Commission (2008). IEC 60317-0-1 Specifications for particular types of winding wires - Part 0-1: General requirements - Enamelled round copper wire. 28 p.

[7] International Electrotechnical Commission (2009b). IEC 60851-2 Winding wire - Test methods - Part 2: Determination for dimensions. $10 \mathrm{p}$.

[8] International Electrotechnical Commission (2009b). IEC 60851-3 Winding wire - Test methods - Part 3: Mechanical properties. $43 \mathrm{p}$.

[9] International Electrotechnical Commission (2010). IEC 60317-13 Specifications for particular types of winding wires - Part 13: Polyester or polyesterimide overcoated with polyamide-imide enameled round copper wire, class 200. 13 p.

[10] International Electrotechnical Commission (2011). IEC 60851-5 Winding wires - Test methods - Part 5: Electrical properties. $30 \mathrm{p}$. 